\title{
VALIDITAS PREDIKTIF UJI KOMPETENSI MAHASISWA PROGRAM PROFESI DOKTER (UKMPPD) PADA TAHAP PROFESI
}

\author{
Irma Suswati, Rahayu \\ Fakultas Kedokteran Universitas Muhammadiyah Malang \\ J1. Bendungan Sutami 188A Malang Telp 0341_552442, Fax 0341_582060 \\ Email : dr_irma_s@yahoo.co.id
}

\begin{abstract}
ABSTRAK
Prosentase ketidaklulusanUji Kompetensi Mahasiswa Program Profesi Dokter (UKMPPD) masih cukup sebesar 44\% - 47\%. Retaker Fakultas Kedokteran Universitas Muhammadiyah Malang (FK-UMM) mengalami peningkatan sebanyak 18 peserta. Upaya untuk menurunkan retaker telah dilakukan. Perlu dikaji prediktor yang mempengaruhi kelulusan UKMPPD yaitu nilai per-bagian, nilai Indeks Prestasi Kumulatif (IPK), nilai Clinical Integration Assesment (CIA), nilai benchmark (BM) dan nilai tryout (TO) AIPKI. Rancangan penelitian diskriptif analitik dengan pendekatan cross sectional. Sampelpenelitian nilai UKMPPD tahun 2016-2017. Pengambilan sampel dengan jalan total sampling. Tempat penelitian di FK-UMM. Data primer menggunakan data nilai UKMPPD sebagai variabel prediktor dan Nilai per-Bagian tahap Profesi, Nilai CIA, Nilai BM, IPK dan nilai TOAIPKI sebagai variabel kriterium. Analisis menggunakan uji korelasi Spearman dan uji regresi. Hasil penelitian menunjukkan bahwa terdapat korelasi antara nilai CBT dengan nilai CIA, BM, TO AIPKI dan IPK, artinya bahwa nilai CBT dipengaruhi nilai CIA, BM, TO AIPKI dan IPK, sedangkan nilai OSCE menunjukan korelasi dengan nilai CIA dan IPK, namun nilai OSCE tidak menunjukkan korelasi dengan BM dan TO AIPKI. Validitas prediktif yang menentukan kelulusan UKMPPD ditentukan oleh IPK, nilai CIA, nilai BM dan nilai TO AIPKI. IPK dan CIA sebagai prediktor UKMPPD CBT dan OSCE, sedangkan BM dan TO AIPKI sebagai prediktor UKMPPD CBT
\end{abstract}

Kata Kunci : Prediktif, Uji, Kompetensi, Profesi

\begin{abstract}
Percentage of National Exam on Medical Students Competency (Uji Kompetensi Mahasiswa Program Profesi Dokter/UKMPPD) is still quite 44\% - 47\%. Re-taker of the Faculty of Medicine University of Muhammadiyah Malang experienced an increase of 18 participants. Attempts to lower the re-taker have been done. It is worth to examine the predictors affecting the UKMPPD graduation: the part score, the grade point average (GPA), the Clinical Integration Assessment (CIA), the benchmark (BM) and the tryout (TO) of AIPKI. Descriptive analytic research design with cross sectional approach. Research sample of UKMPPD value in 2016-2017. Sampling by total sampling. Place of study in FK-UMM. Primary data use UKMPPD value data as predictor variable and the part score, CIA, BM, GPA and TO AIPKI as the criterion variable. The analysis used Spearman correlation test and regression test. The results showed that there was a correlation between CBT and CIA, BM, TO AIPKI and GPA, meaning that CBT were influenced by CIA, BM, TO AIPKI and GPA, while the OSCE showed results with the CIA and GPA, but the OSCE did not show results with BM and TO AIPKI.Predictive validity determining UKMPPD graduation is determined by GPA, CIA, BM and TO AIPKI. GPA and CIA as predictors of UKMPPD CBT and OSCE, while BM and TO AIPKI as predictors of UKMPPD CBT
\end{abstract}

Keywords : Predictive, Test, Competence, Profession 


\section{PENDAHULUAN}

Uji Kompetensi Mahasiswa Program Profesi Dokter (UKMPPD) sebagai exit exam atau kelulusan bagi mahasiswa pendidikan profesi dokter setelah selesai menjalani kepaniteraan klinik di layanan kesehatan. UKMPPD dlaksanakan sebanyak 4 periode pada Bulan Februari, Mei, Agustus dan November dengan jumlah peserta 4000-5000 dari berbagai institusi Pendidikan Dokter di Indonesia dengan prosentase ketidak lulusan sebesar44\% $47 \%$ danyang lulus sebesar $53 \%-55,5 \%$. Peserta retaker Fakultas Kedokteran Universitas Muhammadiyah Malang (FK-UMM) sampai dengan bulan Agustus 2017 mengalami peningkatan sebanyak 18 peserta, walaupun dibandingkan dengan tingkat kelulusan FK-UMM cukup baik mencapai prosentase $87 \%$. Berbagai upaya telah dilaksanakan untuk menurunkan angka ketidaklulusan mulai dari proses pembelajaran di tahap akademik maupun tahap profesi serta dilaksanakannya program ujian tahap akhir yaitu clinical integration assesment (CIA), proses bimbingan sebelum UKMPPD, ujianbenchmark (BM), program bimbingan khusus model "karantina" serta ujian tryout (TO) AIPKI.Menurut analisis Panitia Nasional UKMPPD terhadap tren longitudinal soal CBT, semakin banyak jumlah uji yang dilalui peserta UKMPPD, maka probabilitas kegagalan untuk uji selanjutnya semakin tinggi (rekomendasi Tim Ahli UKMPPD, 2016). Hasil kajian yang dilakukan Suswati, 2017 pada program bimbingan khusus model "karantina" terdapat peningkatan yang signifikan (Sig 0,000) nilai ujian pre-karantina dan post karantina dengan selisih nilai sebesar 6,879 artinya bahwa pelaksanaan bimbingan karantina dapat meningkatkan kemampuan mahasiswa dalam menghadapi UKMPPD. Selain itu hasil penelitian tentang hubungan antara Indeks Prestasi Kumulatif (IPK) dengan UKMPPD yang dilakukan Suswati, 2012; Wicaksono, 2012 dan Selvandega, 2011 menjelaskan bahwa terdapat hubungan yang signifikan antara IPK dengan UKMPPD.

Prosentase Kelulusan UKMPPD atau output yang diharapkan dipengaruhi oleh input dan proses yang dilakukan. Input mahasiswa yang memasuki tahap profesi berasal dari mahasiswa yang telah selesai atau lulus pada tahap akademik sedangkan proses pembelajaran ditahap profesi dengan melakukan berbagai kegiatan profesi perbagian di layanan pelayanan kesehatan. Kegiatan pembelajaran tahap profesi berupa bimbingan langsung (bedsite teaching) tentang penegakan diagnosis, penatalaksanaan pasien gawat darurat dan tidak gawat darurat serta tindakan medis dan non-medis, selain itu melakukan pelayanan kesehatan dalam bentuk promotif, preventif, kuratif maupun rehabilitatif serta kegiatan akademik yaitu diskusi kasus, ilmiah, jurnal reading, morning report dan lain sebagainya, untuk mengetahui tingkat kemampuan mahasiswa ditiap bagian maka dilakukan ujian tulis dan ujian OSCE per-bagian dan disebut dengan lulus yudisium per-bagian jika tidak ada nilai $D$ atau $E$ serta Indeks Prestasi Kumulatif (IPK) lebih dari atau sama dengan 2,75. CIA dilaksanakan setelah mahasiswa menyelesaikan seluruh stase di Rumah Sakit, Puskesmas dan RS Muhammadiyah/Aisyiyah dan mengikuti yudisium Bagian. Program CIA berupa bimbingan dan ujian dalam bentuk OSCE (Objective Structured Clinical Examination)dan MCQ-CBT (Multiple Choice Qouestion Computer Based Testing), dinyatakan lulus dengan nilai batas lulus OSCE lebih dari atau samadengan 50 dan CBT lebih dari atau sama dengan 55. Jika lulus dapat mengikuti program bimbingan dan mengikuti UKMPPD. Proses bimbingan sebelum UKMPPD dilakukan dengan menggunakan sistem peer mentorship yang dibagi menjadi kelompok-kelompok kecil dengan mentor dosen muda atau alumni yang baru lulus UKMPPD. Kegiatan ini dilaksanakan dalam waktu $1-2$ bulan sesuai dengan jadwal setelah lulus saat yudisium CIA. Dalam proses bimbingan tersebut juga dilaksanakan kegiatan ujian progres tes untuk mengukur kegiatan saat bimbingan. Saat bimbingan juga diwajibkan untuk mengikuti BM yaituujian bersama yang dilaksanakan oleh FK Perguruan Tinggi Muhammadiyah (PTM) se Indonesia, soal yang dibuat bersama anggota FKPTM selain itu mengikuti TO AIPKI soal yang dibuat bersama anggota AIPKI. Bagi mahasiswa selama proses bimbingan memerlukan bimbingan khusus maka dilakukan model bimbingan "karantina" yaitu kegiatan bimbingan untuk meningkatkan kemampuan individu mencakup spiritual, moral, kognitif, emosi dan fisik untuk mencapai kondisi yang optimal dalam menghadapi UKMPPD.

Upaya yang telah dilakukan tersebut manakah yang dapat digunakan sebagai prediktor kelulusan UKMPPD ternyata belum dikaji lebih dalam.Apakah nilai yang diperoleh saat mengikuti 
kegiatan per-bagian, nilai IPK, nilai CIA dan nilai BM serta nilai TO AIPKI merupakan prediktor yang dapat mempengaruhi kelulusan UKMPPD? untukmenjawabpermasalahantersebut, makapada penelitian ini ingin mengkajikorelasi hasil UKMPPD dan menentukan validitas prediktif hasil UKMPPD dengan nilai per-bagian, nilai CIA, nilai BM dan nilai TO AIPKI. Manfaat penelitian secara akademik untuk memberikan masukan pada institusi tentang korelasi hasil UKMPPD dengan nilai perbagian, CIA, BM dan TO AIPKI sehingga dapat dipergunakan untukmeningkatkan proses pembelajaran. Selain itu manfaat penelitian ini untuk memberikan informasi pada mahasiswa dan dosen tentang validitas prediktif hasil UKMPPD dengan beberapa prediktor, dengan harapan dapat digunakan untuk motivasi diribagi mahasiswa dan meningkatkan proses pembelajaran dosen pada mahasiswa.

\section{METODE}

Rancanganpenelitian yang digunakan dalam penelitian ini adalah diskriptif analitik dengan pendekatan cross sectional. Populasi dalam penelitian ini adalah nilai UKMPPD. Sampel penelitian nilai UKMPPD tahun 2016-2017 (UKMPPD bulan Agustus 2016, November 2016, Februari 2017, Mei 2017). Pengambilan sampel dengan jalan total sampling. Tempat penelitian di FK-UMM dan waktupenelitianselama 8 bulan. Data primer menggunakan data nilai UKMPPD sebagai variabel prediktordanNilai per-Bagian tahap Profesi,
Nilai CIA, Nilai BM, IPK dan nilai TOAIPKI sebagai variabel kriterium. Skala pengukuran menggunakan skala kategori dan dianalisis menggunakan uji korelasi Spearman (data tidak homogen/normal). Mengetahui validitas prediktif menggunakan uji regresi, menggunakan program SPSS.

\section{HASIL DAN PEMBAHASAN}

\section{Nilai per-Bagian, Nilai CIA, Nilai BM, Nilai TO AIPKI dan Nilai UKMPPD}

Tahap profesi dilakukan dilayanan kesehatan, Rumah Sakit, Puskesmas dan Masyarakat, dengan waktu perbagian 2 sampai 10 minggu dengan total pelaksanaan 90 minggu. Pada stase 10 minggu dilaksanakan di bagian Ilmu Penyakit Dalam (IPD), Obstetri dan Gynecologi (OBG), Bedah dan Ilmu Kesehatan Anak (IKA). Stase 6 minggu dilaksanakan di bagian Saraf, Telinga Hidung Tenggorokan (THT), Mata, Kulit dan Kelamin dan Psikiatri (Jiwa). Stase $2-4$ minggu dilaksanakan di bagian Anestesi, Radiologi, Puskesmas, Foreksik dan Kedokteran Islami dan Kedokteran Industri (KIKI). Rerata nilai per-Bagian seperti pada tabel 1 menunjukkan rerata nila perbagian range 72,14 79,09 dan rerata dengan nilai terendah pada bagian Saraf $(72,14)$ dan Psikiatri $(72,79)$ sedangkan rerata nilai tertinggi di Puskesmas $(79,09)$ dan anestesi $(78,18)$. Berdasarkan rerata per stase menunjukkan bahwa bagian stase 6 minggu memiliki rerta yang rendah 73,47 dan stase 10 minggu 74,01

Tabel 1. Rerata Nilai Per-Bagian

\begin{tabular}{|l|c|c|c|c|c|c|}
\hline \multicolumn{7}{|c|}{ Rerata Nilai Per-Bagian } \\
\hline $\begin{array}{l}\text { Stase 10 } \\
\text { minggu }\end{array}$ & IPD & OBG & BEDAH & IKA & & RERATA \\
\hline & 73,03 & 73,0 & 76,72 & 73,82 & & $\mathbf{7 4 , 0 2}$ \\
\hline $\begin{array}{l}\text { Stase } \\
\text { minggu }\end{array}$ & SARAF & THT & MATA & KULIT & JIWA & \\
\hline & $\mathbf{7 2 , 1 4}$ & 73,89 & 75,13 & 73,38 & $\mathbf{7 2 , 7 9}$ & $\mathbf{7 3 , 4 7}$ \\
\hline $\begin{array}{l}\text { Stase 2-4 } \\
\text { minggu }\end{array}$ & ANEST & RADIO & PUSKES & FOREN & KIKI & \\
\hline & $\mathbf{7 8 , 1 8}$ & $\mathbf{7 5 , 6 4}$ & $\mathbf{7 9 , 0 9}$ & 73,94 & 77,86 & $\mathbf{7 6 , 9 4}$ \\
\hline
\end{tabular}

(Data primer, 2018) 


\section{VALIDITAS PREDIKTIF UJI KOMPETENSI MAHASISWA PROGRAM PROFESI DOKTER 121}

Hasil ujian CIA, BM, TO AIPKI dan nilai UKMPPD (CBT dan OSCE) pada tabel 2. Nilai rerata yang paling rendah TO AIPKI $(61,94)$ tidak mencapai nilai batas lulus nasional (NBL) 66,00. Nilai UKMPPD yang paling tinggi rerata nilai OSCE $(84,25)$ dan nilai CBT $(77,41)$

Tabel 2 Rerata Nilai CIA, BM, TO AIPKI dan UKMPPD

\begin{tabular}{|l|c|c|c|c|c|}
\hline \multicolumn{6}{|c|}{ Rerata Nilai CIA, BM, TO AIPKI dan UKMPPD } \\
\hline Rerata Nilai & CIA & BM & TO AIPKI & \multicolumn{2}{|c|}{ UKMPPD } \\
\cline { 5 - 6 } & & & & CBT & OSCE \\
\hline & 69,14 & 66,15 & 61,94 & 77,41 & 84,25 \\
\hline
\end{tabular}

(Data primer, 2018)

Penilaian hasil belajar menurut Standart Profesi Dokter Indonesia (SPDI, 2012) harus didasarkan pada pencapaian kompetensi yang sesuai dengan Standar Kompetensi Dokter Indonesia (SKDI, 2012) dan proses penilaian hasil belajar dimulai dari perumusan tujuan pembelajaran yang dapat diamati dan diukur (observable and measurable)melalui instrumen yang telah disusun. Hasil penilaian dapat digunakan untuk membuat keputusan mengenai status seseorang peserta didik, lulus atau tidak. (Dirjendikti, 2008). Hasil penilaian juga dapat digunakan untuk memperbaiki proses pembelajaran yang akan datang. (Harsono, 2008). Nilai perbagian rerata diatas 72,00 hal ini menunjukkan bahwa nilai per-bagian nilai huruf $\mathrm{B}$ dan $\mathrm{B}+$ dengan sebutan mutu Baik dan angka mutu 3 dan 3,5 (Panduan Akademik UMM, 2016)

Penilaian dalam pencapaian kompetensi UKMPPD dilakukan dengan uji tulis CBT dan OSCE. Mahasiswa yang lulus uji kompetensi akan memperoleh sertifikat/ijazah dokter yang dikeluarkan oleh Perguruan Tinggi dan sertifikat kompetensi yang dikeluarkan oleh organisasi profesi yaitu Kolegium Dokter Indonesia. Hasil rerata nilai MCQ-CBT $(77,41)$ dan OSCE $(84,25)$ diatas NBL UKMPPD 66,00, hal ini menunjukkan bahwa rerata nilai kelulusan baik.

\section{Korelasi dan validitas prediktif nilai UKMPPD dengan nilai per-bagian}

Hasil uji statistikSpearmandidapatkan bahwa tidak adahubungan antara nilai UKMPPD (CBT dan OSCE) dengan nilai per-bagian (sig $>0,05)$ artinya nilai UKMPPD tidak dipengaruhi oleh nilai masing-masing bagian, namun hasil uji regresi menunjukkan bahwa nilai per-bagian secara keseluruhan merupakan prediktor terhadap nilai CBT sig $0,003 \quad($ sig $<0,05)$ dan OSCE sig 0,038 $($ sig $<0,05)$ pada tabel 3 dan 4 .

Tabel 3 Hasil Regresi Nilai CBT dengan Nilai Per-Bagian

\begin{tabular}{|c|c|c|c|c|c|c|}
\hline \multicolumn{7}{|c|}{ ANOVA $^{a}$} \\
\hline \multicolumn{2}{|c|}{ Model } & $\begin{array}{l}\text { Sum of } \\
\text { Squares }\end{array}$ & Df & Mean Square & $\mathrm{F}$ & Sig. \\
\hline \multirow{3}{*}{1} & Regression & 1083.735 & 14 & 77.410 & 2.497 & $.003^{\mathrm{b}}$ \\
\hline & Residual & 4805.759 & 155 & 31.005 & & \\
\hline & Total & 5889.494 & 169 & & & \\
\hline \multicolumn{7}{|c|}{ a. Dependent Variable: CBT } \\
\hline \multicolumn{7}{|c|}{$\begin{array}{l}\text { b. Predictors: (Constant), KIKI, forensik, jiwa, mata, kep.klinik, puskesmas, kulit, anestesi, } \\
\text { IKA, THT, radiologi, bedah, saraf, OBG }\end{array}$} \\
\hline
\end{tabular}


Tabel 4 Hasil Regresi Nilai OSCE dengan Nilai Per-Bagian

\begin{tabular}{|c|c|c|c|c|c|c|}
\hline \multicolumn{7}{|c|}{ ANOVA $^{a}$} \\
\hline \multicolumn{2}{|c|}{ Model } & Sum of & Df & Mean Square & $\mathrm{F}$ & Sig. \\
\hline \multirow{3}{*}{1} & Regression & 433.470 & 14 & 30.962 & 1.833 & $.038^{\mathrm{b}}$ \\
\hline & Residual & 2618.267 & 155 & 16.892 & & \\
\hline & Total & 3051.737 & 169 & & & \\
\hline \multicolumn{7}{|c|}{ a. Dependent Variable: OSCE } \\
\hline
\end{tabular}

Hal ini menunjukkan bahwa proses pembelajaran ditiap bagian merupakan tahapan yang harus dilalui seorang mahasiswa untuk memperoleh kompetensi sesuai SKDI. Kompetensi yang diperoleh secara keseluruhan di bagian merupakan prediktor yang dapat digunakan untuk menentukan kelulusan UKMPPD (CBT dan OSCE)

\section{Korelasi dan validitas prediktif nilai UKMPPD dengan nilai CIA, BM, TO AIPKI dan IPK.}

Hasil uji Spearmanmenunjukkan terdapat korelasi antara nilai CBT dengan nilai CIA, BM, TO AIPKI dan IPK dengan sig 0,000 (sig<0,05) artinya bahwa nilai CBT dipengaruhi nilai CIA, BM, TO AIPKI dan IPK, sedangkan nilai OSCE menunjukan korelasi dengan nilai CIA sig 0,000 dan IPK sig 0,003 (sig<0,05), namun nilai OSCE tidak menunjukkan korelasi dengan BM sig 0,393 danTO AIPKI sig 0,071. Hal ini menunjukkan bahwa BM dan TO AIPKI tidak mempengaruhi nilai OSCE disebabkan karena BM dan TO hanya menguji tingkat kognitif (knowledge) tanpa menguji psikomotor maupun attitude. CIA dan IPK dalam proses pembelajaran mengajarkan kognitif maupun psikomotor dan attitudedalam bentuk skills labyang merupakan proses pembelajaran untuk mencapai kompetensi sesuai SKDI.

Hasil uji regresi untuk mengetahui nilai yang bersifat prediktif mempengaruhi kelulusan UKMPPD-CBT didapatkan bahwaIPK, BM, CIA dan TO AIPKI mempunyai nilai prediktif yang mempengaruhi kelulusan UKMPPD-CBT dan IPK sig 0,001 merupakan nilai prediktif yang pertama mempengaruhi kelulusan, yang kedua nilai $\mathrm{BM}$ sig 0,016, ketiga nilai CIA sig 0,028 dan yang terakhir nilai TO AIPKI sig 0,041 (tabel 5).Sedangkan nilai prediktif yang mempengaruhi kelulusan UKMPPDOSCE adalah nilai CIA sig 0,000 dan IPK 0,035, sedangkan nilai $\mathrm{BM}$ dan TO AIPKI tidak mempengaruhi nilai OSCE sig $>0,05$ (tabel 6).

Tabel 5 Hasil Regresi Nilai CBT dengan Nilai BM, TO AIPKI, CIA dan IPK

\begin{tabular}{|c|c|c|c|c|c|c|c|c|}
\hline \multicolumn{9}{|c|}{ Coefficients $^{a}$} \\
\hline \multirow{2}{*}{\multicolumn{2}{|c|}{ Model }} & \multicolumn{2}{|c|}{$\begin{array}{c}\text { Unstandardized } \\
\text { Coefficients }\end{array}$} & \multirow{2}{*}{$\begin{array}{c}\begin{array}{c}\text { Standardized } \\
\text { Coefficients }\end{array} \\
\text { Beta }\end{array}$} & \multirow[t]{2}{*}{$\mathrm{T}$} & \multirow[t]{2}{*}{ Sig. } & \multicolumn{2}{|c|}{$\begin{array}{c}\text { Collinearity } \\
\text { Statistics }\end{array}$} \\
\hline & & $\bar{B}$ & Std. Error & & & & Tolerance & VIF \\
\hline \multirow{5}{*}{1} & $($ Cons $\tan t)$ & 17.891 & 8.057 & & 2.221 & .028 & & \\
\hline & BM & .222 & .091 & .222 & 2.442 & .016 & .502 & 1.994 \\
\hline & TO1 & .141 & .069 & .187 & 2.058 & .041 & .505 & 1.982 \\
\hline & CIA & .164 & .074 & .163 & 2.212 & .028 & .765 & 1.307 \\
\hline & IPK & 7.490 & 2.146 & .232 & 3.491 & .001 & .942 & 1.062 \\
\hline
\end{tabular}


Tabel 6 Hasil Regresi Nilai OSCE dengan Nilai BM, TO AIPKI, CIA dan IPK

\begin{tabular}{|c|c|c|c|c|c|c|c|c|}
\hline \multicolumn{9}{|c|}{ Coefficients $^{a}$} \\
\hline \multirow{2}{*}{\multicolumn{2}{|c|}{ Model }} & \multicolumn{2}{|c|}{$\begin{array}{c}\text { Unstandardized } \\
\text { Coefficients }\end{array}$} & \multirow{2}{*}{$\begin{array}{c}\begin{array}{c}\text { Standardized } \\
\text { Coefficients }\end{array} \\
\text { Beta }\end{array}$} & \multirow[t]{2}{*}{$\mathrm{t}$} & \multirow[t]{2}{*}{ Sig. } & \multicolumn{2}{|c|}{$\begin{array}{l}\text { Collinearity } \\
\text { Statistics }\end{array}$} \\
\hline & & $\mathrm{B}$ & Std. Error & & & & Tolerance & VIF \\
\hline \multirow{5}{*}{1} & (Constant) & 59.178 & 6.399 & & 9.248 & .000 & & \\
\hline & $\mathrm{BM}$ & -.103 & .072 & -.144 & -1.431 & .154 & .502 & 1.994 \\
\hline & TO1 & .032 & .055 & .058 & .582 & .561 & .505 & 1.982 \\
\hline & CIA & .262 & .059 & .361 & 4.432 & .000 & .765 & 1.307 \\
\hline & IPK & 3.630 & 1.704 & .156 & 2.130 & .035 & .942 & 1.062 \\
\hline
\end{tabular}

Validitasadalah sejauh mana skor dihasilkan oleh instrumen mengukur karakteristik atau variabel yang dapat digunakan untuk mengukur populasi. Validitas suatu alat ukur adalah sejauh mana alat ukur tersebut mampu mengukur apa yang seharusnya diukur (Azwar, 2000). Validitas terkait kriteria merupakan sebuah ukuran validitas yang ditentukan dengan cara membandingkan skor-skor tes dengan kinerja tertentu pada sebuah ukuran. Hasil validitas kriteria adalah validitas prediktif yaitu kemampuan instrumen pengukuran dalam membedakan populasi dengan referensi pada suatu kriteria masa depan (Sekaran, 2006) dan dapat digunakan untuk seleksi atau klasifikasi personal seperti seleksi, rekruitmen, memprediksi prestasi akademik berdasarkan tes potensi dan sebagainya.

Kelulusan UKMPPD ditentukan dari nilai CBT dan OSCE, disebut lulus jika mencapai NBL yang telah ditetapkan. Hasil penelitian menunjukkan bahwa IPK dan CIA sebagai nilai prediktif yang menentukan kelulusan UKMPPD baik CBT maupun OSCE. Keberhasilan mahasiswa dalam bidang akademik ditandai dengan prestasi akademik yang dicapai dan ditunjukkan melalui IPK. IPK diperoleh dari nilai per-bagian dengan berbagai penilaian seperti nilai $\log$ book, tutorial, refleksi kasus, mini CEX, maupun OSCE. Semakin baik penguasaan akademik mahasiswa maka prestasi yang diperoleh akan baik dan kelulusan UKMPPD makin besar. CIA merupakan salah satu program yang dikembangkan oleh FK UMM dengan kegiatan pembelajaran berupa bimbingan yang mengintegrasikan seluruh bagian dan penilaian berupa CBT dan OSCE. Bimbingan dalam bentuk peer mentorship membahas soal dan diskusi bersama baik dengan pakar maupun tutor, selain soal juga melakukan refreshing skills sesuai dengan kompetensi SKDI. Semakin baik kemampuan mengintegrasikan seluruh bidang ilmu maka semakin besar tingkat kelulusan UKMPPD CBT maupun OSCE.

BM dan TO AIPKI merupakan prediktor kelulusan UKMPPD CBT, namun bukan prediktor yang baik untuk UKMPPD OSCE. BM dan TO AIPKI merupakan penilaian yang hanya menitikberatkan keilmuan (knowledge). BM dapat digunakan sebagai salah satu prediktor UKMPPD CBT oleh karena soal yang diujikan merupakan kumpulan dari beberapa FK PTM sehingga keragaman soal yang dibuat oleh dosen FK PTM lebih bervariasi dibanding soal yang dibuat oleh FK sendiri. Semakin baik kemampuan menyelesaikan soal yang dibuat oleh beberapa FK PTM maka semakin besar tingkat kelulusan UKMPPD CBT. TO AIPKI juga dapat digunakan sebagai prediktor kelulusan UKMPPD CBT namun jika dibandingkan dengan prediktor lain merupakan yang keempat, hal ini kemungkinan karena TO AIPKI dilaksanakan saat mahasiswa belum mengikuti kegiatan pembimbingan yang mengintegrasikan semua bidang ilmu. Jika semakin baik kemampuan menyelesaikan TO AIPKI hal ini menunjukkan bahwa prior knowledge yang dimiliki mahasiswa baik sehingga kelulusan UKMPPD CBT semakin besar.

Nilai IPK dan CIA merupakan instrumen yang bisa digunakan sebagai prediktor kelulusan UKMPPD CBT dan OSCE, sedangkan nilai BM dan TO AIPKI digunakan sebagai prediktor kelulusan UKMPPD CBT saja. Instrumen yang dikembangkan sudah sesuai karena mampu memvalidasi sebagai prediktor kelulusan UKMPPD 
CBT dan OSCE. Proses pembelajaran per-bagian tidak dapat digunakan sebagai prediktor namun menentukan hasil nilai prestasi akademik berupa IPK. Proses pembelajaran yang digunakan untuk CIA, BM dan TO AIPKI baik berupa bimbingan maupun pembahasan melalui diskusi soal dan materi yang dibelajarkan secara terintegrasi seluruh bagian serta instrumen penilaian yang dilakukan untuk CIA, BM dan TO AIPKI juga mampu memvalidasi sebagai prediktor kelulusan UKMPPD.

\section{SIMPULAN}

Hasil penelitian menunjukkan bahwa terdapat korelasi antara nilai CBT dengan nilai CIA, BM, TO AIPKI dan IPK, artinya bahwa nilai CBT dipengaruhi nilai CIA, BM, TO AIPKI dan IPK, sedangkan nilai OSCE menunjukan korelasi dengan nilai CIA dan IPK, namun nilai OSCE tidak menunjukkan korelasi dengan BM dan TO AIPKI. Validitas prediktif yang menentukan kelulusan UKMPPD ditentukan oleh IPK, nilai CIA, nilai BM dan nilai TO AIPKI. IPK dan CIA sebagai prediktor UKMPPD CBT dan OSCE, sedangkan BM dan TO AIPKI sebagai prediktor UKMPPD CBT

\section{DAFTAR PUSTAKA}

Azwar S, 2000. Reliabilitas dan Validitas (Edisi 4) Yogyakarta. Pelajar Pustaka

KonsilKedokteran Indonesia, 2012. Standar Pendidikan Profesi Dokter. Jakarta

Konsil Kedokteran Indonesia, 2012. Standart Kompetensi Dokter. Jakarta

Sekaran U, 2006. Metodologi Penelitian untuk Bisnis. Edisi 4. Buku 1. Jakarta; Salemba Empat

Selvandega WP, Priharsanti N, Kristina, 2011. Hubungan antara Indeks Prestasi Kumulatif dengan Nilai UKDI pada Program Pendidikan Dokter: Studi Kasus di FK Undip. Artikel Karya Tulis Ilmiah.

Suswati I, Prihanti GS, Setiawan I. 2017. Program Bimbingan "Karantina" dalam Meningkatkan Prosentase Kelulusan Uji Kompetensi Mahasiswa Pendidikan Profesi Dokter. Proceeding Annual Meeting APKKM ke-5 ISBN 78-602-6875-53-2
Suswati, 2012. Korelasi Hasil Uji Kompetensi Dokter Indonesia dengan Indeks Prestasi Kumulatif dan Lama Studi. Laporan Penelitian P2I. Malang

Tim Ahli UKMPPD, 2016. Rekomendasi Solusi untuk Penyelesaian Isu Implementasi Uji Kompetensi Mahasiswa Program Profesi Dokter (UKMPPD). Direktorat Jenderal Pembelajaran dan Kemahasiswaan Kementerian Riset, Pendidikan dan Tehnologi

Wicaksono, A. 2012. Hubungan Antara Indeks Prestasi Kumulatif dan Nilai Uji Kompetensi Dokter Indonesia pada Dokter Lulusan Universitas Tanjungpura. Jurnal Visi Ilmu Pendidikan Vol 7, No 1. 